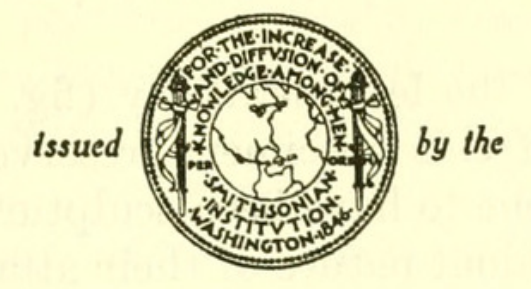

SMITHSONIAN INSTITUTION

U. S. NATIONAL MUSEUM

\title{
A NEW FOSSIL REPTILE FROM THE UPPER CRETACEOUS OF UTAH
}

\section{By Charles W. Gilmore}

In 1939 the Smithsonian Paleontological Expedition discovered the fragmentary skeletal remains of a small reptile in the Upper Cretaceous of the North Horn Mountain area in central Utah. The diminutive size of this individual, its amphicoelous vertebrae, and a dermal armor form a combination of features previously unknown among the extinct Reptilia of the Upper Cretaceous, and although the skeletal remains are meager this unique specimen is described as a new species of a new genus and referred provisionally to the Crocodilia.

PINACOSUCHUS MANTIENSIS, new genus and species

Type--U. S. N. M. No. 16592, consisting of a maxillary fragment, 7 vertebral centra, proximal end of coracoid, shaft of femur, and numerous dermal scutes and spines, with various fragments. Collected in 1939.

Locality.- "Lizard locality," South Dragon, Manti National Forest, Emery County, Utah.

Horizon.-North Horn formation, Upper Cretaceous.

Diagnosis.-Teeth thecodont; vertebrae amphicoelous; two sacraI vertebrae; caudal vertebrae chevron bearing; dermal armor, consisting of sharp, rounded spines; spined, plain, and ridged scutes; limbbone with large medullary cavity. Individual small.

The scanty skeletal materials comprising the type specimen were found in a small cluster on the surface of the exfoliated matrix, and 
as the bones were of corresponding size and there was no apparent duplication of parts it is assumed that all pertain to the skeleton of a single individual.

A small fragment of the left maxillary (fig. 1, $A$ ) is the only recognizable skull part of this specimen preserved. It shows the external surface of the bone to have been sculptured. Alveoli for three teeth indicate the thecodont nature of their attachment and the ovate shape of their roots, with the longer diameter longitudinal.

In all there are seven complete vertebral centra and fragmentary parts of several others. Dorsal, sacral, and caudal vertebrae can certainly be recognized, and there is one centrum that is provisionally identified as pertaining to the axis. It differs from all others in
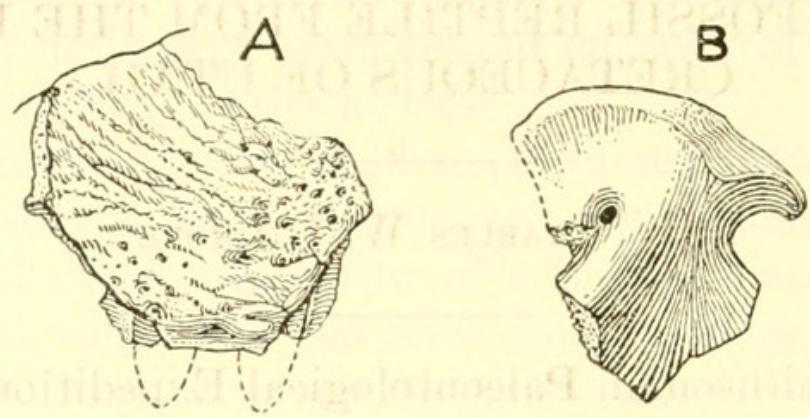

Figure 1.-Skeletal parts of Pinacosuchus mantiensis, type (U. S. N. M. No. 16592): $A$, Maxillary fragment; $B$, proximal end of left coracoid. Both figures three times natcival size.

having a flattened anterior articular end, on each side of which are small facets that look forward and outward. This centrum is depressed and is wider in front than behind, with a broadly rounded ventral surface as shown in figure 2 . The posterior articular end is cupped. The centrum has a greatest length of $9 \mathrm{~mm}$. and a greatest width of $7.5 \mathrm{~mm}$.

Two dorsal centra differ in that one is compressed and the other depressed. It is thought that the former pertains to the anterior dorsal region, the latter to the posterior part of the presacral series. Both have small portions of the neural arch present, but the absence of any trace of the sutural connections with the centra suggests the adult age of the individual. Both have evenly rounded ventral surfaces without trace of a keel. The anterior dorsal centrum measures $8 \mathrm{~mm}$. in length, the posterior one $7 \mathrm{~mm}$.

The two sacral centra (fig. 3) were found detached from each other, but their roughened sutural ends made perfect articulation. These centra have a combined length of $14.3 \mathrm{~mm}$. The centra are depressed, with cupped, ovate, articular ends and broadly rounded ventral surfaces. Sacral ribs attach with the center of the centra. 
The anterior caudal centrum, shown in figure 4, $A$, has quadrangular cupped ends and portions of heavy, transverse processes. The ventral surface is shallowly channeled longitudinally. A second caudal centrum (figure $4, B$ ) is more elongated than the one previously mentioned. Its ventral surface is also shallowly channeled, with distinctly developed chevron facets on the posterior end. It is

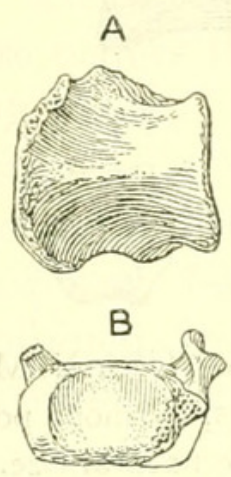

Figure 2.-Centrum of ?axis of Pinacosuchus mantiensis, type (U. S. N.M. No. 16592): $A$, Ventral view; $B$, anterior view. Both figures twice natural size.

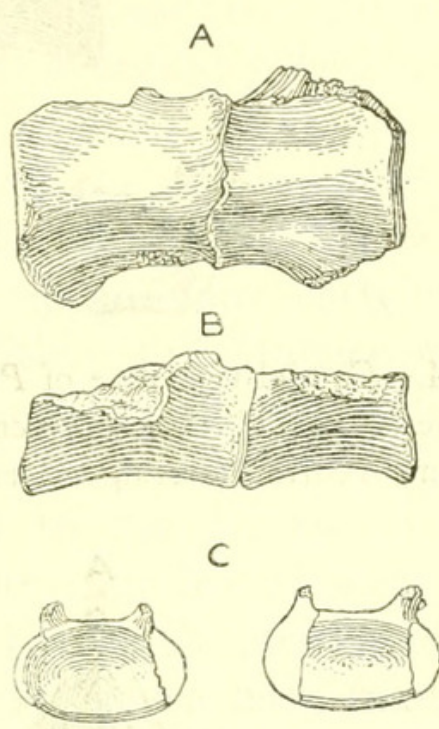

Figure 3.-Sacrum of Pinacosuchus mantiensis, type (U. S. N. M. No. 16592): $A$, Ventral view; $B$, lateral view; $C$, end Views. All figures twice natural size.

evident that this vertebra also bore transverse processes, thus indicating that it belonged to the anterior half of the tail.

Coracoid.-The articular end of a flat bone (fig. 1, B) perforated by a circular foramen is tentatively identified as the proximal portion of the left coracoid. Except for the scapular border being convex, it has its closest resemblance with the coracoid of the crocodile. It shows the same transverse thickening of the articular contribution to the glenoid socket and the same hooklike process overhanging the missing shaft of the bone, below the glenoid cavity. The placement of the coracoid foramen is similar.

Femur.-The bent shaft of a limb bone preserved with this specimen is provisionally identified as being that of a femur. It has a large medullary cavity and at the center is round in cross section.

Dermal ossifications.-The dermal armor of Pinacosuchus mantiensis displays no less than five different types of ossification: (1) Simple, thin, flat, rectangular scutes; (2) ridged rooflike scutes (fig. $5, C$ ); (3) thickened subrectangular scutes, having sharp, asymmetrically placed spine that strongly overhangs the borders (fig. $5, D$ ); (4) small pointed spines with thickened bases (fig. $5, A$ ); (5) more elongate pointed spines with thickened bases (fig. 5, B). All have sculptured surfaces. 
A
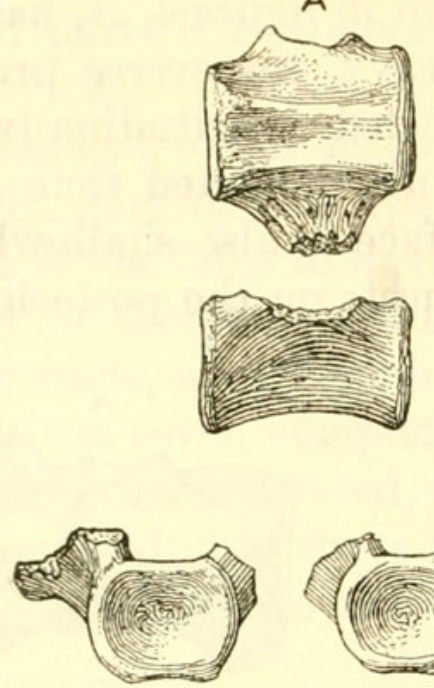

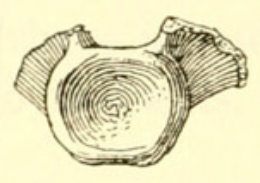

$B$
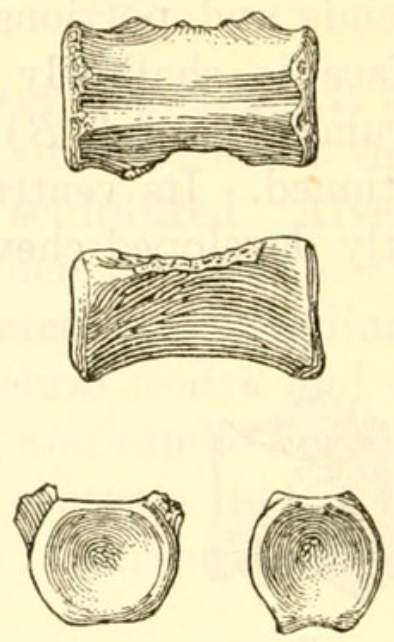

Figure 4.-Caudal vertebrae of Pinacosuchus mantiensis, type (U. S. N. M. No. 16592): $A$, Anterior caudal centrum, ventral, lateral, and end views; $B$, more posterior caudal centrum, ventral, lateral, and end views. All figures twice natural size.
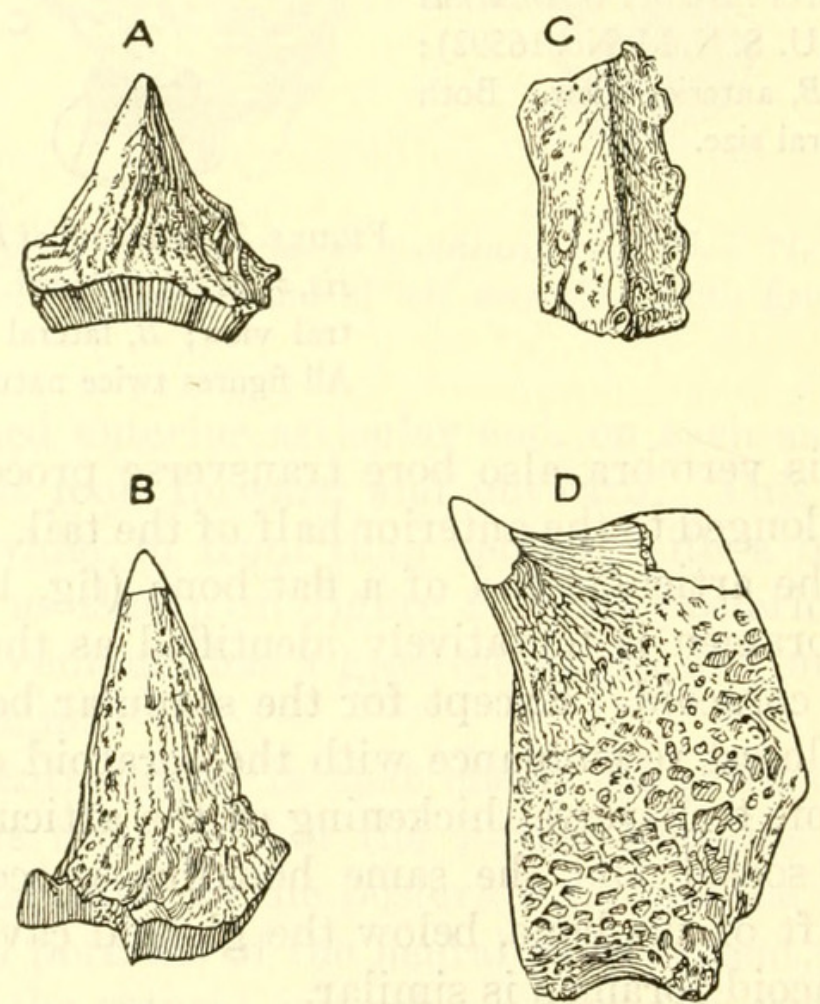

Figure 5.-Dermal spines and scutes of Pinacosuchus mantiensis, type (U. S. N. M. No. 16592): $A$, Short spine; $B$, elongate spine; $C$, ridged scute; $D$, asymmetrical spined scute. All three times natural size.

All these dermal structures were found disassociated in the matrix, and thus no clue has been obtained as to the disposition or arrangement of these ossifications in the skin. That they were a portion of an elaborate ornamentation is clearly evident. 


\section{RELATIONSHIPS}

At the present time so little is known of the skeletal structure of Pinacosuchus mantiensis that $\mathrm{I}$ have been unable to arrive at a satisfactory conclusion as to its true ordinal affinities. Of the 14 reptilian orders recognized by Woodward ${ }^{1}$ the specimen under discussion can be satisfactorily eliminated from 10 . This leaves the Squamata, Thecodontia, Crocodilia, and Dinosauria, and it is in one of these orders that this specimen will eventually find a permanent resting place.

The presence of a thecodont dentition and the amphicoelous vertebrae would appear to rule it out of the Squamata, for with the exception of the Gekkota, which have amphicoelous vertebrae but always combined with an acrodont dentition and absence of bony scutes, all other lizards and all other members of the order have procoelous vertebrae.

That this specimen could be referred to the Dinosauria seems highly improbable, for although the primary number of sacral vertebrae in this order may have been two, no Upper Cretaceous dinosaur is known having less than five, and several genera have many more than that. This reason alone would appear sufficient to exclude Pinacosuchus.

The order Thecodontia is a generalized group from which it is thought by some authorities that both the Crocodilia and the Dinosauria may have been derived, but the suborder Pseudosuchia contains a considerable number of lizard-shaped land reptiles of small size that have such a diversity of structure that their location here must be regarded as provisional. As a repository for genera of uncertain ordinal affinities the Pseudosuchia would seem to be the logical reference of Pinacosuchus. The few structural features known would not be in particular discord with such an assignment, but the fact that all the referred genera are of Triassic age or older leads one to doubt the advisability of such an assignment.

Amphicoelian crocodilians are known to have persisted into the Upper Cretaceous (Benton), and the present specimen presents a few characteristics that suggest crocodilian relationships. Reference is made to the thecodont dentition, sacrum of two vertebrae, presence of bony skin scutes, close resemblance of incomplete coracoid to that of the crocodile, and a sculpture of the maxillary surface closely simulating that of many crocodilians. Meager and unsatisfactory though the evidence may be, none of the more important characters

' Woodward, A. Smith, Zittel's "Textbook of Paleontology," vol. 2, pp. 233-427, 1932. 
displayed by the present materials except the ornate character of the scutes are opposed to its inclusion in the Crocodilia, and therefore Pinacosuchus is provisionally referred to this order until such time as the discovery of more complete specimens shall disclose its true ordinal relationships. 


\section{$2 \mathrm{BHL}$ Biodiversity Heritage Library}

Gilmore, Charles W. 1942. "A new fossil reptile from the Upper Cretaceous of Utah." Proceedings of the United States National Museum 93(3158), 109-114. https://doi.org/10.5479/si.00963801.93-3158.109.

View This Item Online: https://www.biodiversitylibrary.org/item/31779

DOI: https://doi.org/10.5479/si.00963801.93-3158.109

Permalink: https://www.biodiversitylibrary.org/partpdf/20462

\section{Holding Institution}

Smithsonian Libraries

\section{Sponsored by}

Smithsonian

\section{Copyright \& Reuse}

Copyright Status: NOT_IN_COPYRIGHT

Rights: https://www.biodiversitylibrary.org/permissions/

This document was created from content at the Biodiversity Heritage Library, the world's largest open access digital library for biodiversity literature and archives. Visit BHL at https://www.biodiversitylibrary.org. 